\title{
Clinical features, pathological findings and outcome of children admitted to a tertiary care paediatric hospital with Epstein-Barr virus infection
}

\author{
*Abu Bakkar Siddique ${ }^{1}$, Kallol Bose ${ }^{1}$, Sudip Saha ${ }^{1}$, Kallol Das ${ }^{1}$, Chanchal Kumar Kundu ${ }^{1}$, Sutapa \\ Ganguly $^{1}$, Piyashi Mondal ${ }^{1}$
}

Sri Lanka Journal of Child Health, 2017; 46(3): 243-247

\begin{abstract}
Introduction: Epstein-Barr virus (EBV) infection most commonly manifests as acute infectious mononucleosis but is usually asymptomatic.
\end{abstract}

Objective: To describe the clinical features, pathological findings and outcome of children admitted to a tertiary care paediatric hospital with EBV infection.

Method: The study group included children who were admitted with various presentations of EBV such as dengue like illness, prolonged fever, myocarditis, encephalitis and haemophagocytic lymphohistiocytosis (HLH) over the last 3 years.

Results: In our study, $16(45.7 \%)$ children had a dengue like illness, $5(14.3 \%)$ had myocarditis, 1 (2.9\%) had HLH, 2 (5.7\%) had encephalitis and 11 $(31.4 \%)$ had prolonged fever.

Conclusions: Dengue like illness and prolonged fever were the 2 most frequent presentations of EBV infection.

DOI: http://dx.doi.org/10.4038/sljch.v46i3.8326

(Key words: Epstein-Barr virus, myocarditis, dengue, encephalitis, HLH, children, fever)

\section{Introduction}

Epstein-Barr virus (EBV) is a gamma herpesvirus ${ }^{1}$. It commonly manifests as acute infectious mononucleosis affecting adolescents and young adults ${ }^{1}$. In young children EBV is usually asymptomatic or mild ${ }^{1}$. EBV is rarely associated with lymphoproliferative disorders and tumours such as nasopharyngeal carcinoma and Burkitt lymphoma ${ }^{2}$.

${ }^{1}$ Chittaranjan Seva Sadan, India
${ }^{*}$ Correspondence: abu89.cmc@gmail.com

(Received on 06 December 2016: Accepted after revision on 20 January 2017)

The authors declare that there are no conflicts of interest

Personal funding was used for the project.

Open Access Article published under the Creative

Commons Attribution CC-BY CC

\section{Objective}

To describe the clinical features, pathological findings and outcome of children admitted to a tertiary care paediatric hospital with EBV infection.

\section{Method}

The study group included children who were admitted to the Chittaranjan Seva Sadan hospital, a tertiary care paediatric hospital in India, with various presentations of EBV such as dengue like illness, prolonged fever ( $>7$ days), myocarditis, encephalitis and haemophagocytic lymphohistiocytosis over the last 3 years. We suspected EBV infection in the following categories of patients:

1. Patients having fever, rash, anasarca, with or without serositis and bleeding or thrombocytopenia and shock where all investigations including blood culture, dengue and chikungunya serology were found to be negative.

2. Patients with respiratory distress presenting with features of congestive heart failure (CHF) where common causes of CHF such as structural heart disease, rheumatic fever, influenza, coxsackie B, cytomegalovirus, rubella, parvovirus and metabolic causes had been ruled out.

3. Patients with features of meningoencephalitis with rash where other common pathogens had been ruled out by cerebrospinal fluid (CSF) analysis, culture, serology, and polymerase chain reaction (PCR).

4. In cases of haemophagocytic lymphohistiocytosis (HLH).

5. In cases of prolonged fever ( $>7$ days) presenting with or without rash, cervical, axillary, inguinal, epitrochlear lymphadenopathy, organomegaly where all common causes have been excluded by blood, throat and urine culture, malaria, dengue, typhoid serology, antinuclear antibody, abdominal ultrasonography of abdomen, echocardiography and lymph node biopsy (in selected cases).

For diagnosis of EBV infection, IgM and $\operatorname{IgG}$ antibody against viral capsid antigen (VCA) were sent. Positive IgM type of antibody was taken as 
recent EBV infection. We collected data of positive cases, tabulated them and analyzed. We classified presentations of EBV infection into five groups:

A. Dengue like illness - fever, rash, generalized oedema with or without serositis, features of shock

B. Encephalitis

C. HLH

D. Myocarditis

E. Prolonged fever

False positive results with antibody against EBV viral capsid antigen are very rare. Sensitivity and specificity are $94.7 \%$ and $96.1 \%$ respectively ${ }^{3}$.

\section{Results}

Dengue like illness was diagnosed in 16 patients. The ages ranged from 9 months to 12 years. We excluded dengue fever by sending Dengue Ns 1 and Dengue RT-PCR (before 5 days) and Dengue IgM antibody (after 7 days). The clinical and laboratory features of the 16 patients are shown in Table 1.

Table 1

Clinical signs \& laboratory parameters of patients with dengue like illness $(n=16)$

\begin{tabular}{|l|c|}
\hline \multicolumn{1}{|c|}{ Characteristic } & Number (\%) \\
\hline $\begin{array}{l}\text { Gender } \\
\text { Fale }\end{array}$ & $08(50.0)$ \\
Female & $08(50.0)$ \\
\hline Rash & $06(37.5)$ \\
\hline Hepatomegaly & $14(87.5)$ \\
\hline Splenomegaly & $02(12.5)$ \\
\hline Lymphadenopathy & $06(37.5)$ \\
\hline Ascites & $16(100.0)$ \\
\hline Generalised oedema & $16(100.0)$ \\
\hline $\begin{array}{l}\text { Pleural effusion } \\
\text { Bilateral }\end{array}$ & $11(68.7)$ \\
Unilateral & $05(31.3)$ \\
\hline $\begin{array}{l}\text { Haemoglobin level } \\
<10 \mathrm{~g} / \mathrm{dl} \\
<7 \mathrm{~g} \text { dd }\end{array}$ & $13(81.0)$ \\
\hline $\begin{array}{l}\text { Platelet count } \\
<150,000 / \text { cu mm }\end{array}$ & $07(43.8)$ \\
\hline $\begin{array}{l}\text { White blood cell count } \\
<4,000 / \text { cu mm }\end{array}$ & $12(75.0)$ \\
\hline Pancytopenia & $04(25.0)$ \\
\hline Elevated SGPT & $03(18.7)$ \\
\hline Elevated serum creatinine & $07(43.8)$ \\
\hline SGPT- sermm glutamicpyruic & $02(12.5)$ \\
\hline
\end{tabular}

*SGPT- serum glutamic pyruvic transaminase

The 7 patients whose haemoglobin was below $7 \mathrm{~g} / \mathrm{dl}$ were given packed cell transfusion with $15 \mathrm{ml} / \mathrm{kg}$ of packed red blood cell (PRBC). The $9(56 \%)$ children who needed no transfusion of $\mathrm{PRBC}$, in the second week of admission showed some rise in the haemoglobin level. Of the $12(75 \%)$ patients with low platelet counts, in 9 cases the platelet counts were elevated spontaneously above $150,000 / \mathrm{cu} \mathrm{mm}$ in the second week. Platelet transfusions were given if the platelet was below $10,000 / \mathrm{cu} \mathrm{mm}$ or below $40,000 / \mathrm{cu} \mathrm{mm}$ with active bleeding. In fact, 3 $(18.7 \%)$ patients needed platelet transfusions. Of the $04(25 \%)$ patients with leucopenia, 3 had neutrophilic dominance. Pancytopenia $(\mathrm{Hb}<10 \mathrm{~g} / \mathrm{dl}$, $\mathrm{WBC}<4000 / \mathrm{cu} \mathrm{mm}$, platelet $<150,000 / \mathrm{cu} \mathrm{mm}$ ) was detected in $03(18.7 \%)$ patients. Of the $7(43.7 \%)$ children with raised serum glutamic pyruvic transaminase (SGPT) on admission, only one case had elevation of SGPT in the second week. Echocardiography was normal in all patients. Patients were treated with Ringer lactate solution 4$20 \mathrm{ml} / \mathrm{kg}$ depending on packed cell volume (PCV) and vital signs. All recovered without sequel except one who later developed features of encephalitis.

Two patients presented with encephalitis. Both were female, aged 9 years and 12 years respectively. They presented with a history of fever, rash and altered sensorium. The first one had generalized tonic clonic seizures (GTCS) on day 6 and the second one had GTCS on day 10. Both had hepatomegaly but splenomegaly was present in only one patient. One patient had cervical lymphadenopathy. Both had low haemoglobin and low platelet levels but in the second week the haemoglobin and platelet counts were raised. Both patients had normal white blood cell counts. SGPT was persistently increased in both patients. Cerebrospinal fluid (CSF) of the first patient was normal but the second patient had lymphocytic pleocytosis with normal protein and sugar. Magnetic resonance imaging (MRI) showed cerebral oedema in the first child but could not be done in the second child. Electroencephalograms (EEGs) and echocardiograms of both patients were normal. They were managed conservatively and treatment of raised intracranial pressure was given. First patient recovered but second patient expired after the $16^{\text {th }}$ day of fever.

One male patient, aged 2 year and 3 months, presented with fever and rash on day 5, hepatosplenomegaly and cervical lymphadenopathy. Initially complete blood count was normal and the erythrocyte sedimentation rate (ESR) was raised. In the $2^{\text {nd }}$ week pancytopenia occurred and ESR decreased along with high serum ferritin and triglyceride levels. The bone marrow showed haemophagocytosis and a diagnosis of HLH was made. Treatment was given with dexamethasone $10 \mathrm{mg} / \mathrm{m}^{2}$ and gradually tapered over 3 months along with etoposide.

Five patients presented with features of myocarditis. The ages ranged from 9 months to 1 year and 8 months. The clinical and laboratory features of the 5 patients are shown in Table 2. 
Table 2

Clinical signs and laboratory parameters of patients with myocarditis $(n=5)$

\begin{tabular}{|c|c|}
\hline Characteristic & No. (\%) \\
\hline Gender & \\
\hline Male & $03(60)$ \\
\hline Female & $02(40)$ \\
\hline Preceding coryza & $05(100)$ \\
\hline Rash & $02(40)$ \\
\hline Hepatomegaly & $05(100)$ \\
\hline Splenomegaly & $01(20)$ \\
\hline Lymphadenopathy & \\
\hline Cervical only & $02(40)$ \\
\hline Axillary only & $01(20)$ \\
\hline Cervical + Axillary & $01(20)$ \\
\hline Low haemoglobin level & $04(80)$ \\
\hline Low platelet count & $04(80)$ \\
\hline Elevated SGPT & $03(60)$ \\
\hline Elevated lactate dehydrogenase & $05(100)$ \\
\hline Elevated troponin- $T$ & $05(100)$ \\
\hline Elevated troponin-I & $01(20)$ \\
\hline Elevated creatinine phosphokinase & $03(60)$ \\
\hline
\end{tabular}

*SGPT- serum glutamic pyruvic transaminase

In the $2^{\text {nd }}$ week the $\mathrm{Hb}$ and platelet levels normalised without transfusion. Sinus tachycardia was noted in the electrocardiograms (ECGs) in all patients and in $01(20 \%)$ patient ST segment elevation was noted. Cardio-thoracic ratio in X-Ray was increased in all patients. All patients had very low ejection fraction varying from $20 \%$ to $40 \%$. Inotrope support, immunoglobulin and other conservative managements were given. Three $(60 \%)$ of them needed ventilator support. Out of five patients 04 $(80 \%)$ patients recovered but one died. Three of them were given dopamine and levosimendan. Two were treated with dopamine and milrinone.

Eleven patients between ages of 1 year to 12 years presented with a history of prolonged fever $(>7$ days). The clinical and laboratory features of the 11 patients are shown in Table 3.

Table 3

Clinical signs \& laboratory parameters of patients with prolonged fever $(n=11)$

\begin{tabular}{|l|c|}
\hline \multicolumn{1}{|c|}{ Characteristic } & Number (\%) \\
\hline Gender & $06(55.0)$ \\
Male & $05(45.0)$ \\
Female & $05(45.0)$ \\
\hline Rash & $10(90.9)$ \\
\hline Hepatomegaly & $07(63.0)$ \\
\hline Splenomegaly & $06(54.0)$ \\
\hline Lymphadenopathy & $09(81.8)$ \\
\hline Low haemoglobin level & $04(36.3)$ \\
\hline Low platelet count & $08(72.7)$ \\
\hline Elevated SGPT &
\end{tabular}

*SGPT- serum glutamic pyruvic transaminase
One patient had inguinal abscess and one had knee and elbow abscess and these were drained. Of the 9 patients with low $\mathrm{Hb}$ at presentation, there was an increase in 8 of them in the $2^{\text {nd }}$ week. While the platelet counts were initially low in 4 patients, they increased spontaneously in the $2^{\text {nd }}$ week. Other investigations for fever (blood, urine, throat culture, antinuclear antibody, rheumatoid factor, dengue (NS1, IgM), typhidot IgM, Mantoux test, Gastric lavage for cartridge based nucleic acid amplification test (CBNAAT), human immunodeficiency virus (HIV) serology, echocardiograph, ultrasonogram of abdomen were negative. All patient recovered with conservative management. Maximum duration of fever was twenty-nine days.

\section{Discussion}

EBV infected patients generally present with fever, headache, sore throat, nausea, abdominal pain and myalgia ${ }^{4}$. In our study, $16(45.7 \%)$ had a dengue like illness, $5(14.3 \%)$ had myocarditis, $1(2.9 \%)$ had HLH, 2 (5.7\%) had encephalitis and $11(31.4 \%)$ had prolonged fever. Dengue like illness has been reported with other viruses such as chikungunya, but never with EBV. Neurological manifestations are seen in less than $1 \%$ of EBV infection ${ }^{5}$. Among these, meningitis and encephalitis constitute the most common types of neurological manifestations. The patients may have varied symptoms like fever, seizure, bizarre behaviour, headache, and metamorphopsia ${ }^{6}$. The presenting signs included altered consciousness, meningeal signs, bulbar signs cerebellar signs and cranial nerve palsy ${ }^{7}$. Two of our cases who presented with encephalitis had altered sensorium with rash, GTCS and altered sensorium. Meningeal signs and cranial nerve palsy were not noted. MRI showed diffuse cerebral oedema in one case who had normal EEG and CSF. The other child whose CSF showed lymphocytic pleocytosis, progressed to deep coma and expired and MRI could not be done.

One of our patients presented with fever, rash and hepatosplenomegaly with normal complete blood count but in the $2^{\text {nd }}$ week developed pancytopenia, elevated serum ferritin and triglyceride levels and the bone marrow showed haemophagocytosis. He was diagnosed as HLH and treated with dexamethasone and etoposide. In EBV induced $\mathrm{HLH}$, there is a deficiency in producing EBV specific cytotoxic $\mathrm{T}$ cells due to infected primary CD8+ cells, suggesting an impaired or absent function of NK cells and cytotoxic T cells ${ }^{8}$. These cytotoxic $\mathrm{T}$ cells are needed to regulate $\mathrm{EBV}$ infected B cells. Due to poor regulation of B cells there is persistence of EBV infection. Thus, there is a sustained immune response with persistently high pro-inflammatory cytokines levels (such as interferon $\gamma$, tumor necrosis factor $\alpha$, interleukin 6 , $8,10,16,18$, and macrophage colony stimulating 
factor) leading to haemophagocytosis and multi organ failure ${ }^{9,10}$.

Significant cardiac involvement in infectious mononucleosis is extremely rare. Tachycardia is the rule. The most common changes in electrocardiogram (ECG) are abnormalities of the ST segment and as seen in one patient. Myocarditis caused by EBV infection may become fatal in young patients, especially in children. EBV can cause one single episode or repetitive myocarditis resulting either in congestive heart failure ${ }^{10}$ or in complete heart block $^{12}$. We had 5 cases of EBV-induced myocarditis with elevated cardiac enzymes, left ventricular hypokinesia with low ejection fraction (EF) $(20 \%$ to $40 \%)$. Four out of five patient recovered but one patient died. Eleven patients presented with a history of prolonged fever (>7days). Whilst hepatomegaly was present in $91 \%$ of them, rash was present in only $45 \%$, splenomegaly in $63 \%$ and lymphadenopathy in 54\%. All patient recovered with conservative management. In EBV infection generalized lymphadenopathy (90\%), splenomegaly (10\%) hepatomegaly $(10 \%)$ are $\operatorname{seen}^{4}$. In our study, lymphadenopathy was present in $42.8 \%$, splenomegaly in $34.2 \%$ and hepatomegaly in $91.4 \%$ cases.

\section{References}

1. Dunmire SK, Hoqquist KA, Balfour HH. Infectious mononucleosis. Current Topics in Microbiology and Immunology 2015; 390 (Pt 1): 211-40.

https://doi.org/10.1007/978-3-319-22822-

89

PMid: 26424648 PMCid: PMC4670567

2. Ali AS, Al-Shraim M, Al-Hakami AM, Jones IM. Epstein-Barr virus: Clinical and epidemiological revisits and genetic basis of oncogenesis. Open Virology Journal 2015; 9: 7-28.

https://doi.org/10.2174/187435790150901

0007

PMid: 26862355 PMCid: PMC4740969

3. Pumannová M, Rezbová M, Svecová M, Hrbácková H, Novotná M, Ochotná $\mathrm{J}$, et al. A comparison of the detection of IgM antibodies against the viral capsid antigen (VCA) of EBV (Epstein-Barr virus) in various groups of patients, using indirect immunofluorescence, indirect ELISA and reverse ELISA. Study of the diagnostic efficacy of the anti-VCA EBV IgM ELISA-VIDITEST kit. Klin Mikrobiol Infekc Lek 2004; 10(4):186-90. PMid: 15328576
4. Jenson HB. Epstein-Barr Virus In: Kliegman RM, Stanton BF, St Geme III JW, Schor NF, Behrman RE, editors. Nelson Textbook of Pediatrics. $20^{\text {th }}$ ed. Philadelphia: Elsevier; 2016.p.1586-90.

5. Li ZY, Lou JG, Chen J. Analysis of primary symptoms and disease spectrum in Epstein-Barr virus infected children. Zhonghua Er Ke Za Zhi 2004; 42:20-2.

PMid: 14990099

6. Doja A, Bitnun A, Jones EL, Richardson S, Tellier R, Petric M, et al. Paediatric Epstein-Barr virus-associated encephalitis: 10-year review. Journal of Child Neurology 2006; 21(5):385-91.

PMid: 16948923

7. Kleines M, Schiefer J, Stienen A, Blaum M, Ritter K, Häusler M. Expanding the spectrum of neurological disease associated with Epstein-Barr virus activity. European Journal of Clinical Microbiology and Infectious Diseases 2011; 30(12): 1561-9. https://doi.org/10.1007/s10096-011-12617

PMid: 21573818

8. Kasahara Y, Yachie A. Cell type specific infection of Epstein-Barr virus (EBV) in EBV-associated haemophagocytic lymphohistiocytosis and chronic active EBV infection. Critical Reviews in Oncology/ Haematology 2002; 44(3):28394.

https://doi.org/10.1016/S10408428(02)00119-1

9. Janka GE. Haemophagocytic syndromes. Blood Reviews 2007; 21(5):245-53. https://doi.org/10.1016/j.blre.2007.05.001 PMid: 17590250

10. Rouphael NG, Talati NJ, Vaughan C, Cunningham $\mathrm{K}$, Moreira R, Gould $\mathrm{C}$. Infections associated with haemophagocytic syndrome. Lancet. Infectious Diseases 2007; 7(12):814-22. https://doi.org/10.1016/S14733099(07)70290-6

11. Hebert MM, Yu C, Towbin JA, Rogers BB. Fatal Epstein Barr virus myocarditis in a child with repetitive myocarditis. Pediatric Pathology and Laboratory Medicine 1995; 15:805-12. 
https://doi.org/10.3109/155138195090270

16

PMid: 8597866

12. Reitman MJ, Zirin HJ, DeAngelis CJ. Complete heart block in Epstein-Barr myocarditis. Pediatrics 1978; 62:847-9.

PMid: 214746 